Article

\title{
Optimization of the TEGs Configuration (Series/Parallel) in Energy Harvesting Systems with Low-Voltage Thermoelectric Generators Connected to Ultra-Low Voltage DC-DC Converters
}

\author{
Flávio Morais ${ }^{1}(0)$, Pedro Carvalhaes-Dias ${ }^{2}{ }^{\circ}$, Luís Duarte ${ }^{2}{ }^{\oplus}$, Anderson Spengler ${ }^{3}{ }^{\circledR}$, \\ Kleber de Paiva ${ }^{3}$, Thiago Martins ${ }^{3}\left(\mathbb{D}\right.$, Andreu Cabot ${ }^{4,5}$ and José Siqueira Dias ${ }^{6, *(D)}$ \\ 1 Faculty of Science and Engineering, São Paulo State University Júlio de Mesquita, \\ Tupã, SP 17602-496, Brazil; flavio.morais@unesp.br \\ 2 Department of Electrical Engineering-DAELE, Universidade Tecnológica Federal do Paraná (UTFPR), \\ Cornélio Procópio, PR 86300-000, Brazil; pcdias@utfpr.edu.br (P.C.-D.); lfduarte@utfpr.edu.br (L.D.) \\ 3 Department of Mobility Engineering, Federal University of Santa Catarina, Joinville, SC 89219-600, Brazil; \\ anderson.spengler@ufsc.br (A.S.); Kleber.paiva@ufsc.br (K.d.P.); t.m.thiago.martins@posgrad.ufsc.br (T.M.) \\ 4 Catalonia Institute for Energy Research-IREC, 08930 Barcelona, Spain; acabot@irec.cat \\ Catalan Institution for Research and Advanced Studies-ICREA, 08010 Barcelona, Spain \\ 6 Department of Semiconductors, Instrumentation and Photonics-DSIF/FEEC, University of Campinas, \\ Campinas, SP 13083-852, Brazil \\ * Correspondence: siqueira@demic.fee.unicamp.br; Tel.: +55-19-35214901
}

Received: 27 March 2020; Accepted: 28 April 2020; Published: 6 May 2020

\begin{abstract}
Solar radiation and human activity generate ubiquitous temperature gradients that could be harvested by thermoelectric generators (TEGs). However, most of these temperature gradients are in the range of very few degrees and, while TEGs are able to harvest them, the resulting output voltages are extremely small (a few hundreds of $\mathrm{mV}$ ), and DC-DC converters are necessary to boost them to usable levels. Impedance matching between TEGs and DC-DC converter plays a fundamental role in the energy harvesting efficiency. Therefore, it is essential to determine the output power of the system in different configurations, in order to decide on the optimum TEG connection. Here, we present an electronic circuit to measure the maximum power that can be harvested with low-voltage TEGs connected to a DC-DC converter. The developed circuit is an electronic controlled load that drains the maximum current from the output of the DC-DC converter while maintaining its output voltage at the maximum allowed value. Using a mechanical set-up able to apply precise low temperature gradients between the hot and cold side of the TEGs, experimental data using different configurations of TEGs are obtained. The measured results show that, for ultra-low voltages, the TEG ensemble's output impedance plays an important role not only in the amount of the energy scavenged, but also in the onset temperature of the energy harvesting.
\end{abstract}

Keywords: energy harvesting; thermoelectric generators; energy measurement; series and parallel TEGs ensemble; ultra-low voltage DC-DC converters

\section{Introduction}

Thermoelectric energy harvesting is a simple, robust, and cost-efficient solution to scavenge energy from temperature gradients generated by solar radiation and human activity, among others $[1,2]$. Energy harvesting with thermoelectric generators (TEGs) has been mostly explored for applications where large temperature gradients are available, like engines, industrial furnaces, or exhaust pipes, and several applications powered by TEGs have been presented in the literature. 
As an example, TEG coupled to the exhaust gas of a vehicle was demonstrated to improve the efficiency in cold-starts [3] and to improve the fuel economy [4]. TEGs fabricated in silicon chips have been proposed for integrated systems (TEG, sensors, RF circuits) [5]. Silicon TEGs with 127 legs presented a Seebeck coefficient of approximately $20 \mathrm{mV} / \mathrm{K}$, a value that is close to the typical $30 \mathrm{mV} / \mathrm{K}$ found in a similar commercial TEG fabricated with $\mathrm{Bi}_{2} \mathrm{Te}_{3}$. Using ceramic substrates, hybrid circuits with nanostructured resistors were integrated with a TEG, leading to an autonomous heat dissipation soil water content sensor for use in agriculture [6].

Flexible thermoelectric generators have been presented as a solution to power wearable and implantable devices, harvesting the body heat. The current challenges and suggestions for future developments of flexible TEGs are presented and discussed in [7]. An autonomous multi-sensor (temperature, relative humidity and solar radiation) powered by a solar thermoelectric energy harvester was developed in [8]. Due to the small temperature gradients, a ultra-low power management circuit was developed to allow a continuous operation of the sensors system. The use of the latent heat stored in the ground was studied at different latitudes in [9], and it was found that, in some days, the energy harvested due to the heat stored in the ground is comparable to the energy scavenged by the solar radiation.

However, energy harvesting with thermoelectric generators (TEGs) of ubiquitous environmental heat is extremely challenging because of the small temperature gradients involved, which results in low TEG output voltages [7-9]. The energy harvested by such systems critically depends on the performance of the DC-DC converters used, since the efficiency of these converters vary from approximately $60 \%$ to $20 \%$ when the input voltage changes from $10 \mathrm{mV}$ to $150 \mathrm{mV}$.

In addition, low input voltage DC-DC converters, like the EM8900 from EM Microelectronic (Marin, Switzerland) [10] or the LTC3108 from Analog Devices (Norwood, MA, USA) [11], present large variations of the input impedance. For example, the EM8900 can present an input impedance that varies from approximately $0.7 \Omega$ to $35 \Omega$, depending on its input power and programmed output voltage.

When the temperature difference across the TEG is high and the output power is measured directly at its output terminals, an ensemble with TEGs connected electrically in series provides a higher power than when the TEGs are connected in parallel [12].

The output power in [12] was measured using a conventional scheme, as shown in Figure 1. In this scheme, a constant gradient temperature is applied to the TEG and the load $R_{L}$ is varied, while the TEG current $I_{L}$ and output voltage $V_{L}$ are measured. From the measured values of $I_{L}$ and $V_{L}$, the output power $P=V_{L} I_{L}$ is calculated. The maximum output power is obtained when the internal impedance of the TEG is equal to the impedance of the external load.

(a)

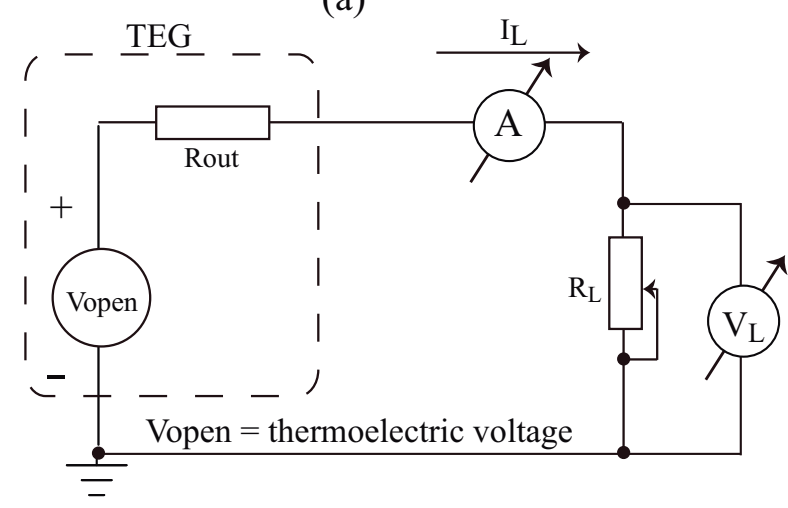

(b)

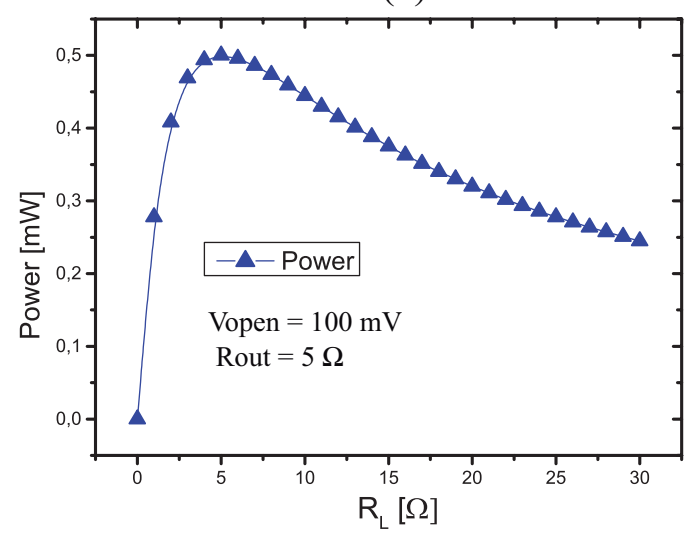

Figure 1. (a) scheme for measuring the power of a TEG; (b) plot of output power as a function of the external load $R_{L}$, for $V_{\text {open }}=100 \mathrm{mV}, R_{\text {out }}=5 \Omega$. 
However, when designing a harvesting system that requires an ultra-low voltage DC-DC converter, it is not clear to the designer if it is better to use an ensemble of TEGs electrically connected in series (higher voltage but also a higher TEG output impedance) or in parallel, with a lower voltage and also a lower TEG output impedance.

To determine which TEG's configuration optimizes the energy harvesting system in what concerns: (a) temperature gradient necessary for the onset of energy harvesting; and (b) temperature gradient necessary to achieve maximum power, we propose here a laboratory test, connecting the DC-DC converter to an electronic circuit, which drains the maximum current from the DC-DC converter output while maintaining its output voltage at the maximum value.

To apply the desired temperature difference across the TEGs, a proper system was specially designed and fabricated. With this set-up, we were able to apply well controlled temperatures to up to sixteen TEGs, all thermally connected in parallel. To make the tests, we connect the TEGs externally in electrical parallel and series configurations.

The steady-state current supplied by the DC-DC converter is measured for each tested configuration, so that the best solution in what concerns cost and efficiency can be easily found.

\section{Materials and Methods}

\subsection{The DC-DC Converter}

As the temperature gradients available from the environment are very low, we tested a thermoelectric harvesting system with an ultra-low voltage DC-DC converter, the EM8900 that operates from input voltages in the range of $5 \mathrm{mV}$ to $200 \mathrm{mV}$. A conventional DC-DC converter with the EM8900 was designed, using the suggested configuration in the data-sheet. The implemented circuit is shown in Figure 2. The EM8900 accepts step-up transformers with 1:20, 1:50, and 1:100 turn ratios. Since we intend to test ultra-low voltage systems, we used the LPR6235-752SMR (1:100) transformer, from Coilcraft (Cary, IL, USA) [13].

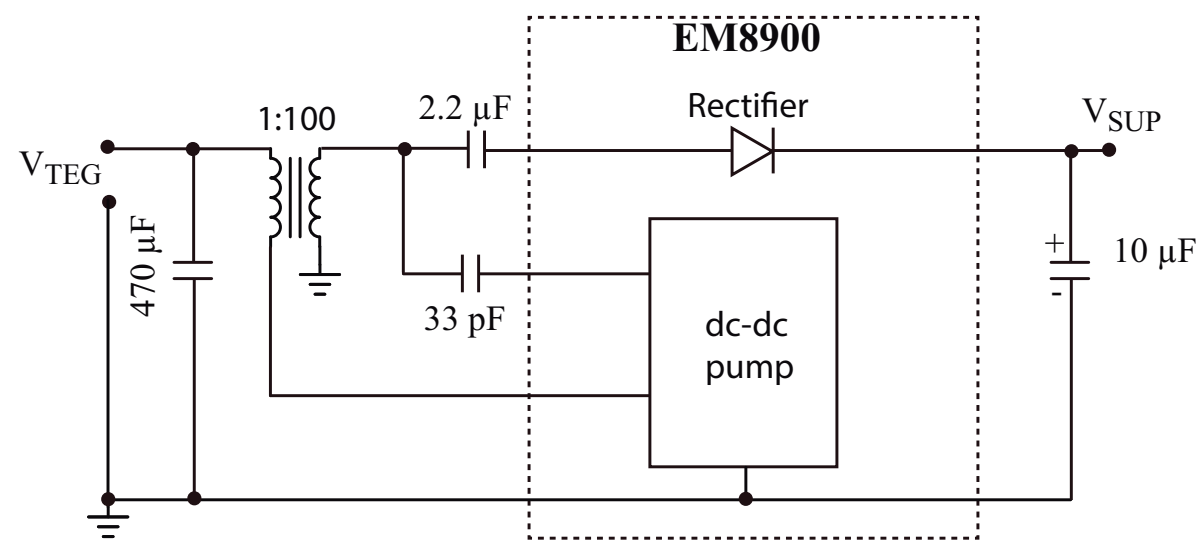

Figure 2. Implemented DC-DC converter using the EM8900.

\subsection{Thermal System}

Measuring the efficiency of TEGs systems is a complex task, and various configurations of automatic measurement rigs were presented in the literature [14-18]. In order to characterize the ensemble of thermoelectric generators with a stable temperature gradient, the apparatus presented in Figure 3 was developed. This mechanical system is able to provide accurate temperatures (measured with previously calibrated thermocouples) to each side of the TEGs under test.

The TEG ensemble was sandwiched between two copper blocks $B 1$ and $B 2$, each block being in contact with a thermoelectric cooler (TEC1 and TEC2). The top side of both TECs was in contact with a copper heat sink (HS1 and HS2), which were alcohol-cooled by a Lauda ETK-30 chiller unity 
(from Lauda, Lauda-Königshofen, Germany). Six thermocouples were fitted through the copper blocks (three in each block), each touching the surfaces of the TEG ensemble under test.

In this system, the thermocouples signals are measured with a $0.02{ }^{\circ} \mathrm{C}$ resolution, with a NI9214/TB9214 thermocouple module (from National Instruments (Austin, TX, USA)). Since we are measuring small temperature gradients (up to $3.5^{\circ} \mathrm{C}$ ), all thermocouples were previously characterized, using a platinum RTD. The thermocouple module output signal is sent to a PC, where it is corrected by a software, using the characterization data, and the actual temperature is calculated. The calculated temperatures are used in the PC that runs a PID routine (using LabView (Austin, TX, USA)) that controls the temperature on both sides of the TECs. The PID output signals are sent to a PCB with a microcontroller that generates a PWM signal and drives two H-bridges circuits, applying the required power to the TECs.

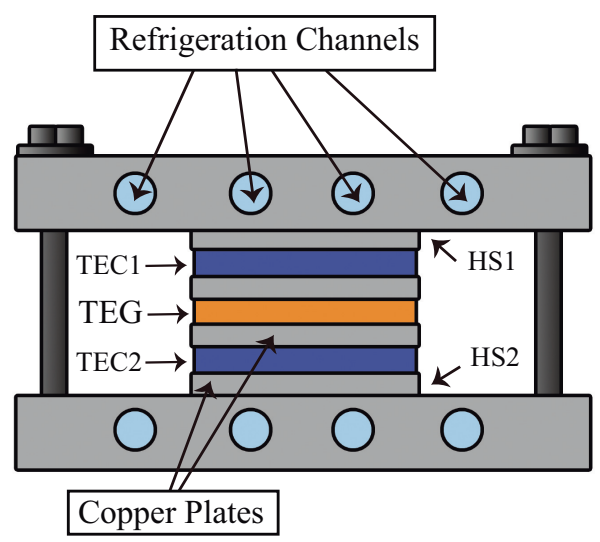

(a)

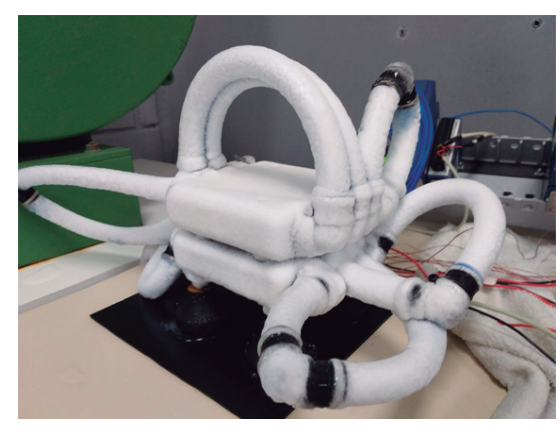

(b)

Figure 3. Experimental test rig: (a) diagram; (b) photograph.

It is worth observing that the TEGs were measured with a reference temperature (cold side of the TEGs) of $T_{r e f}=27.1^{\circ} \mathrm{C}$. The ice seen in Figure $3 \mathrm{~b}$ is formed on the copper heat sinks (HS1 and HS2) and in the cooling pipes, which are in contact with the hot side of the thermoelectric coolers, removing the generated heat.

\subsection{Power Measurement Circuit}

An interesting characteristic of the EM8900 is that its maximum output voltage must be controlled by the external load, and its maximum value is $V_{\text {sup }}=4.2 \mathrm{~V}$. Thus, a limiting device must be used to avoid $V_{\text {sup }}>4.2 \mathrm{~V}$. Therefore, to guarantee that the DC-DC converter is supplying its maximum output power, we need an electronic load that drains the maximum current from the EM8900, while still maintaining $V_{\text {sup }}=4.2 \mathrm{~V}$ at its output.

The block diagram of the electronic load is presented in Figure 4. The output voltage of the DC-DC converter $\left(V_{\text {sup }}\right)$ goes to the unity gain buffer $A 2$, and then it is sent to a voltage divider formed by $R 1, R 2$, resulting in a voltage $V_{a}$. This voltage $V_{a}$, proportional to $V_{\text {sup }}$, is fed back to the non-inverting input of $A 1$, so that the current source is controlled to force the output voltage of the DC-DC converter $V_{\text {sup }}$ to be at a value that makes $V_{a}=V_{\text {ref }}$.

The voltage $V_{a}$ is fed back to the non-inverting input of $A_{1}$ because there is an inversion inside the feedback loop (the voltage $V_{a}$ decreases as the $A_{1}$ output increases), and the connection of $V_{a}$ to the non-inverting input of $A_{1}$ results in an effective negative feedback.

Op-amp $A 1$ has a voltage $V_{\text {ref }}$ applied to its inverting input. The op-amp output drives a voltage controlled current source $I_{0}$. The current $I_{0}$ passes through shunt resistor $R_{0}$; the voltage in $R_{0}$ is amplified by the instrumentation amplifier $A_{0}$ and measured with a voltmeter. 


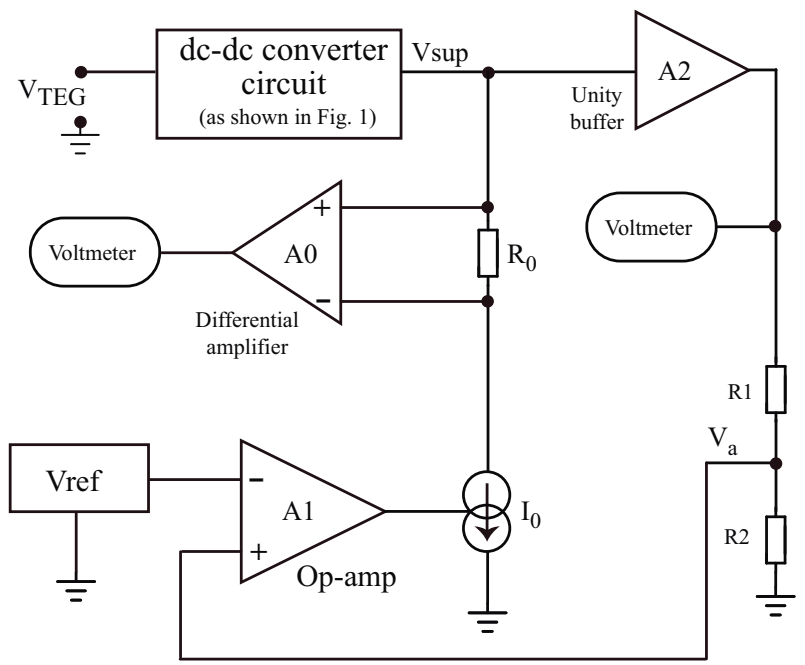

Figure 4. Block diagram of the measurement circuit that performs also as an electronic load circuit.

Although sophisticated current measurement circuits are necessary when a very high dynamic range has to be measured [19], in our experiment, the measured current range was small (from approximately $1 \mu \mathrm{A}$ to $250 \mu \mathrm{A}$ ), we used a conventional technique (also shown in [19], where the voltage on a shunt resistor is measured. The steady-state current supplied by the DC-DC converter flows into a shunt resistor and the voltage in the shunt resistor is amplified by an instrumentation amplifier and can be measured with a voltmeter. The output voltage of the DC-DC converter can also measured with a voltmeter, and the power furnished by the DC-DC converter is calculated.

Using the scheme shown in Figure 4, we guarantee that, if the voltage supplied by the TEG is enough to obtain $V_{\text {sup }}=4.2 \mathrm{~V}$, the value of the controlled current $I_{0}$ will be always at the maximum value that maintains this condition. If the output voltage of the DC-DC converter does not reach $V_{\text {sup }}=4.2 \mathrm{~V}$, the current in $Q_{1}$ decreases, trying to let $V_{\text {sup }}$ increase and reach $V_{\text {sup }}=4.2 \mathrm{~V}$. Since it will not be possible (as the DC-DC converter cannot furnish $V_{\text {sup }}=4.2 \mathrm{~V}$ even without load), the current decreases until it reaches zero, and the power furnished by the DC-DC converter is zero.

The implemented circuit is shown in Figure 5. An LT6004 (dual rail-to-rail operational amplifiers, from Analog Devices (Norwood, MA, USA)) is used to implement both the unity gain buffer $A_{2}$ and the error amplifier $A_{1}$.

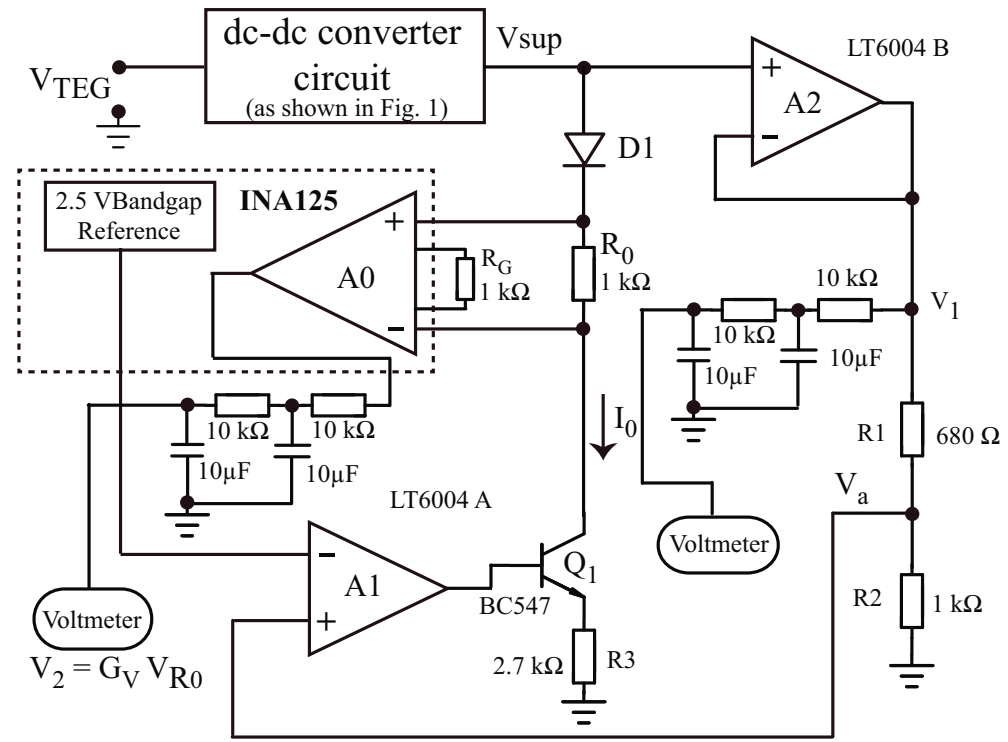

Figure 5. Measurement circuit developed. 
The voltage controlled current source is built with a simple bipolar transistor $Q_{1}$ and an emitter resistor $R_{3}$. An external $V_{c c}=5 \mathrm{~V}$ power supply was used to power the op-amps (they are powered with $5 \mathrm{~V}$ and $\mathrm{Gnd}$ ), so that, neglecting the input currents in $A_{0}$ and in the non-inverting input of $A_{2}$, all the output current from the DC-DC converter is sink by $I_{0}$.

The differential amplifier, implemented with a single supply instrumentation amplifier (INA125 from Texas Instruments (Dallas, TX, USA)), was designed to have a gain $G_{V}=34\left(R_{G}=1000 \Omega\right)$ and was powered by the same $5 \mathrm{~V}$ external power supply. The INA125 has a low off-set voltage (typically $\pm 50 \mu \mathrm{V}$ ) and since a $1 \mu \mathrm{A}$ current creates a voltage of $1 \mathrm{mV}$ in the shunt resistor, and the value of the off-set was neglected. The INA125 gain expression $\left(G_{V}=4+60 \mathrm{k} / R_{G}\right)$ is specified with an error of only $\pm 0.05 \%$, so we measured the real values of the gain $G_{V}$ to calculate the power in Equation (1). Depending on the input voltage and impedance applied to the DC-DC converter, we can observe a small ripple in its output, so we added a simple second order passive R-C low-pass filter to the output of the INA125, in order to obtain a very stable dc voltage $V_{2}$, which will be measured to calculate the EM8900 output current. Another second order R-C filter was used in the output of $A_{2}$, so the voltage $V_{1}$ will also present a low ripple when measured.

The input common-mode range of the INA125 is limited on the negative side to $0.25 \mathrm{~V}$, and to $0.8 \mathrm{~V}$ on the positive side. The DC-DC converter output is controlled to be at $4.2 \mathrm{~V}$ (exactly $0.8 \mathrm{~V}$ below $V_{c c}$ ), so we added an extra voltage drop of approximately $0.6 \mathrm{~V}$ (diode $D_{1}$ ) to guarantee that the INA125 will operate with input voltages within the specified range with respect to the positive supply. Concerning the negative supply, since the voltage drop on $R_{0}$ is less than $200 \mathrm{mV}$, the lower side of $R_{0}$ will be at approximately $3.4 \mathrm{~V}$, well within the negative side specified range.

By measuring, in steady-state, the voltages $V_{2}$ and $V_{1}$, remembering that, if the circuit is working properly, $V_{1}$ must be approximately $4.2 \mathrm{~V}$ (it depends on the accuracy of the voltage divider $R_{1}, R_{2}$ and on the reference voltage $V_{R E F}$ ), we can calculate the power that is being furnished by the DC-DC converter as:

$$
P=V_{1} \frac{V_{2}}{G_{V} R_{0}}
$$

where

$$
\frac{V_{2}}{G_{V} R_{0}}=I_{0}
$$

A photograph of the implemented circuit is shown in Figure 6.

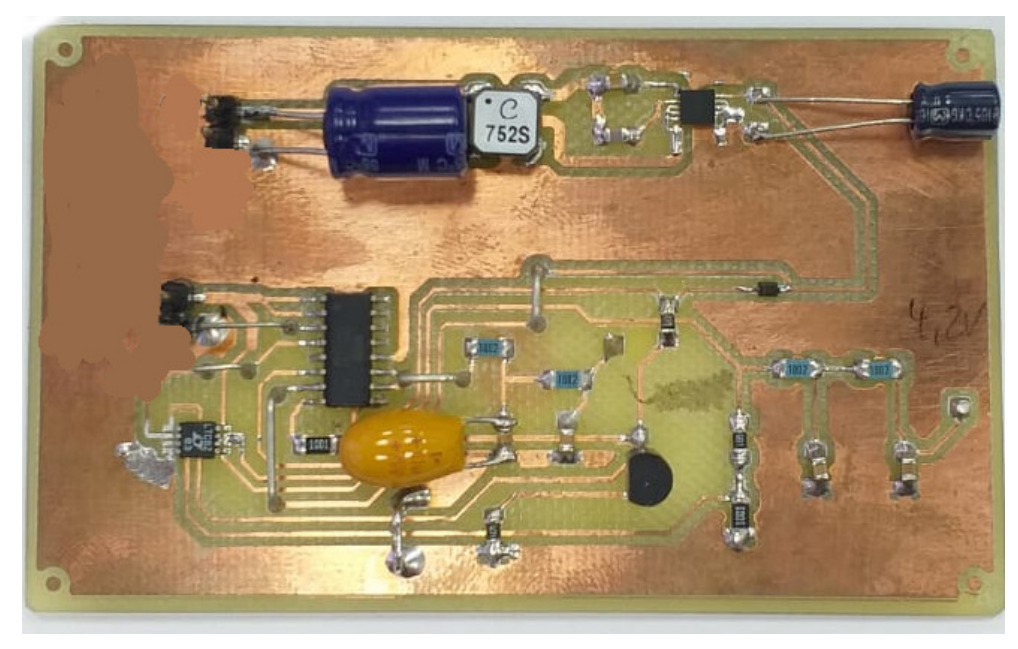

Figure 6. Photograph of the measurement circuit fabricated. 


\section{Experimental Results}

\subsection{Proof-of-Concept Test}

The measurement circuit was implemented and the proof-of-concept test was performed, to verify if our assumption that the TEG output impedance can play a critical role in the efficiency of the DC-DC converter. The TEGs' open voltages were emulated using a programmable voltage source (Keithley 230) and the output impedance of the TEG ensemble were implemented with conventional resistors. The measurement set-up is presented in Figure 7.

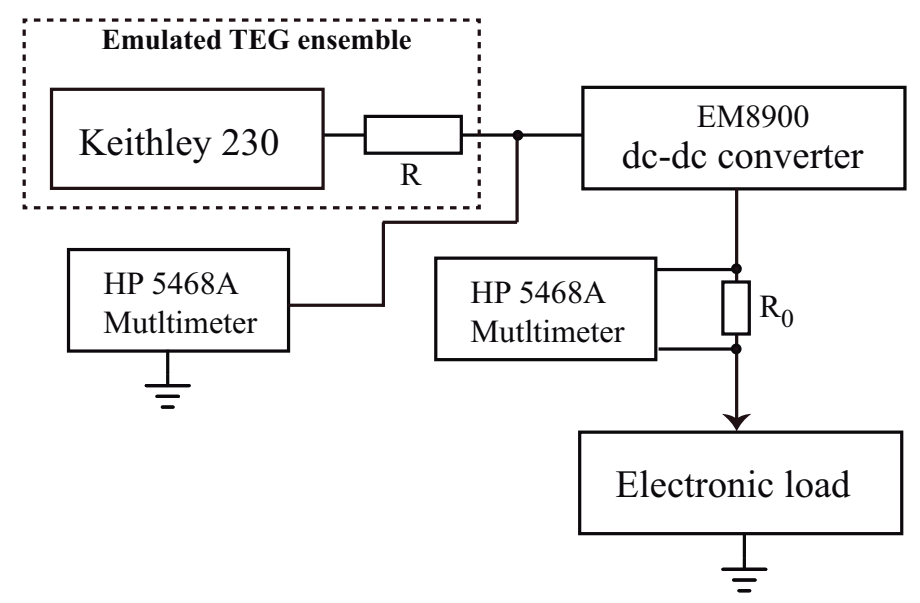

Figure 7. Proof-of-concept measurement set-up.

In this test, we measured, for a fixed TEG open circuit voltage $\left(V_{i n}=165 \mathrm{mV}\right)$, the voltages $V_{1}$ and $V_{2}$ using a two HP5468A digital multimeter, and calculated the DC-DC converter output power (using Equation (1)), with several resistors emulating the TEG's output impedances $Z_{\text {out }}$, in the range 2.1 to $35.5 \Omega$. The calculated results of the output power are plotted in Figure 8.

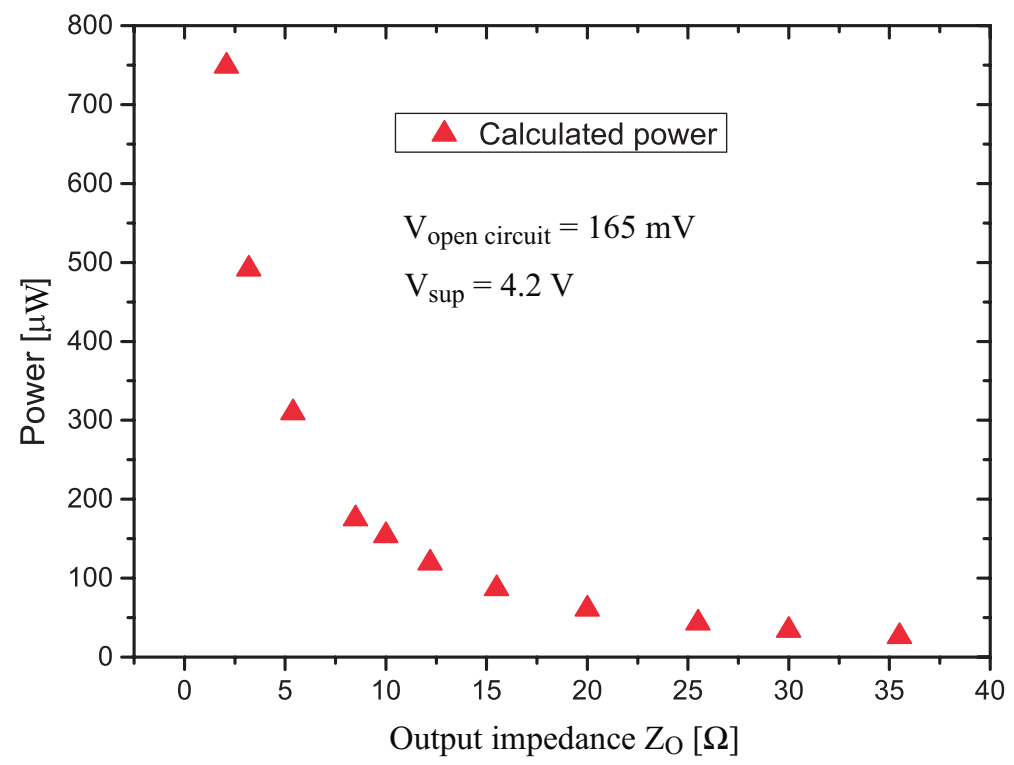

Figure 8. Calculated DC-DC converter output power with a fixed input voltage $\left(V_{\text {in }}=165 \mathrm{mV}\right)$ and series resistors in the range 2.1 to $35.5 \Omega$.

From this test, we observed that the output impedance of the TEG indeed plays a critical role in the performance of an ultra-low voltage DC-DC converter. Thus, we raised the hypothesis that a lower output voltage of an ensemble of parallel electrically connected TEGs (which has a lower output 
impedance) can perform better than an ensemble of series connected TEGs that have a higher output voltage but also have a much higher output impedance.

In this work, all tests were performed with the components shown in Figure 2. It is important to notice that, with an input voltage $V_{\text {in }}=165 \mathrm{mV}$ (which is close to the maximum allowed, $200 \mathrm{mV}$ ) and a TEG impedance of $2.1 \Omega$, this DC-DC converter can furnish a maximum output power $P_{\text {out }} \approx 0.76 \mathrm{~mW}$.

\subsection{Tests with TEGs}

Since the EM8900 starts working with very low input voltages, the thermal system shown in Figure 3 was used to supply well controlled and precise temperature gradients between the hot and cold sides of the TEGs. We tested the system with several parallel and series configuration of up to three TEGs (TEG241-1.0-1.2 from Everredtronics (Shanghai, China)). In this test, the voltages $V_{1}$ and $V_{2}$ were measured using the analogue to digital converters of the NI9214. Table 1 presents the tested configurations.

Table 1. Tests performed with the system.

\begin{tabular}{cl}
\hline Test \# & Configuration \\
\hline 1 & 1 single TEG \\
2 & 2 TEGs in series \\
3 & 2 TEGs in parallel, in series with 1 TEG \\
4 & 3 TEGs in series \\
5 & 2 TEGs in parallel \\
6 & 3 TEGs in parallel \\
\hline
\end{tabular}

Since the measurement system is fully automatized, it was started with a zero temperature gradient. The temperature gradient was raised very slowly $\left(0.5^{\circ} \mathrm{C} / \mathrm{min}\right)$ and all measurements (temperature gradient with the thermocouples and voltages $V_{1}$ and $V_{2}$ ) were continuously acquired. We calculated the output power of the DC-DC converter in each test (using Equation (1)), and the results are presented in Figure 9. Since current in $Q_{1}$ is not zero only when $V_{\text {sup }}=4.2 \mathrm{~V}$, the values of output power were obtained with $V_{\text {sup }}=4.2 \mathrm{~V}$.

From the data shown in Figure 9a (test \#1, with one single TEG), we notice that the output power of the EM8900 remained zero until the temperature cross the TEG reached approximately $\Delta T \approx 1.7^{\circ} \mathrm{C}$, and reached a maximum $\left(P_{\text {out }} \approx 1.02 \mathrm{~mW}\right.$ ) when the temperature gradient was $\Delta T \approx 2.5^{\circ} \mathrm{C}$. It is worth remembering that, as shown in the proof-of-concept test, the maximum power that this DC-DC converter can furnish is limited, and, in this test, we see that it is around $P_{\text {out }} \approx 1 \mathrm{~mW}$.

With two TEGs in series (Figure 9b, test \#2), the onset operation of the EM8900 occurred at a much lower temperature gradient $\left(\Delta T \approx 0.5^{\circ} \mathrm{C}\right)$, but the higher input impedance of the two TEGs in series results in the maximum output power being reached only with $\Delta T \approx 3.25{ }^{\circ} \mathrm{C}$.

It is interesting to notice that one additional series TEG drastically reduces the onset of the operation of the EM8900 (from $\Delta T \approx 1.7{ }^{\circ} \mathrm{C}$ to $\Delta T \approx 0.5^{\circ} \mathrm{C}$ ), but, on the other hand, due to the higher output impedance of the series configuration, to achieve the maximum output power, a $40 \%$ higher temperature gradient is necessary.

The plot presented in Figure 9c (from test \#3, 2 TEGs in parallel in series with 1 TEG) shows results obtained from a configuration with two series TEGs in series with a third TEG. This configuration has the same voltage potential of the configuration with two series TEGs (test \#2, Figure 9b), but the configuration of test \#3 has a lower impedance (due to the paralleling of two TEGs). This changes significantly the performance of the system. The operation onset of the EM8900 in test \#3 is reduced from $\Delta T \approx 0.5^{\circ} \mathrm{C}$ to $\Delta T \approx 0.18{ }^{\circ} \mathrm{C}$, and the maximum power is reached at a much low temperature gradient, only $\Delta T \approx 1.8^{\circ} \mathrm{C}$, whereas, in test $\# 2$, a temperature gradient of $\Delta T \approx 3.25^{\circ} \mathrm{C}$ was necessary.

Surprisingly, when we have three TEGs in series (Figure $9 \mathrm{~d}$, test \#4), the operation onset is similar to the cases where we have only two TEGs, and the only explanation for this is because of the higher 
output impedance in the series TEGs). However, the maximum power is achieved with $\Delta T \approx 2.25^{\circ} \mathrm{C}$, showing that this configuration does not perform as well as the configuration with the same number of TEGs in (test \#3).
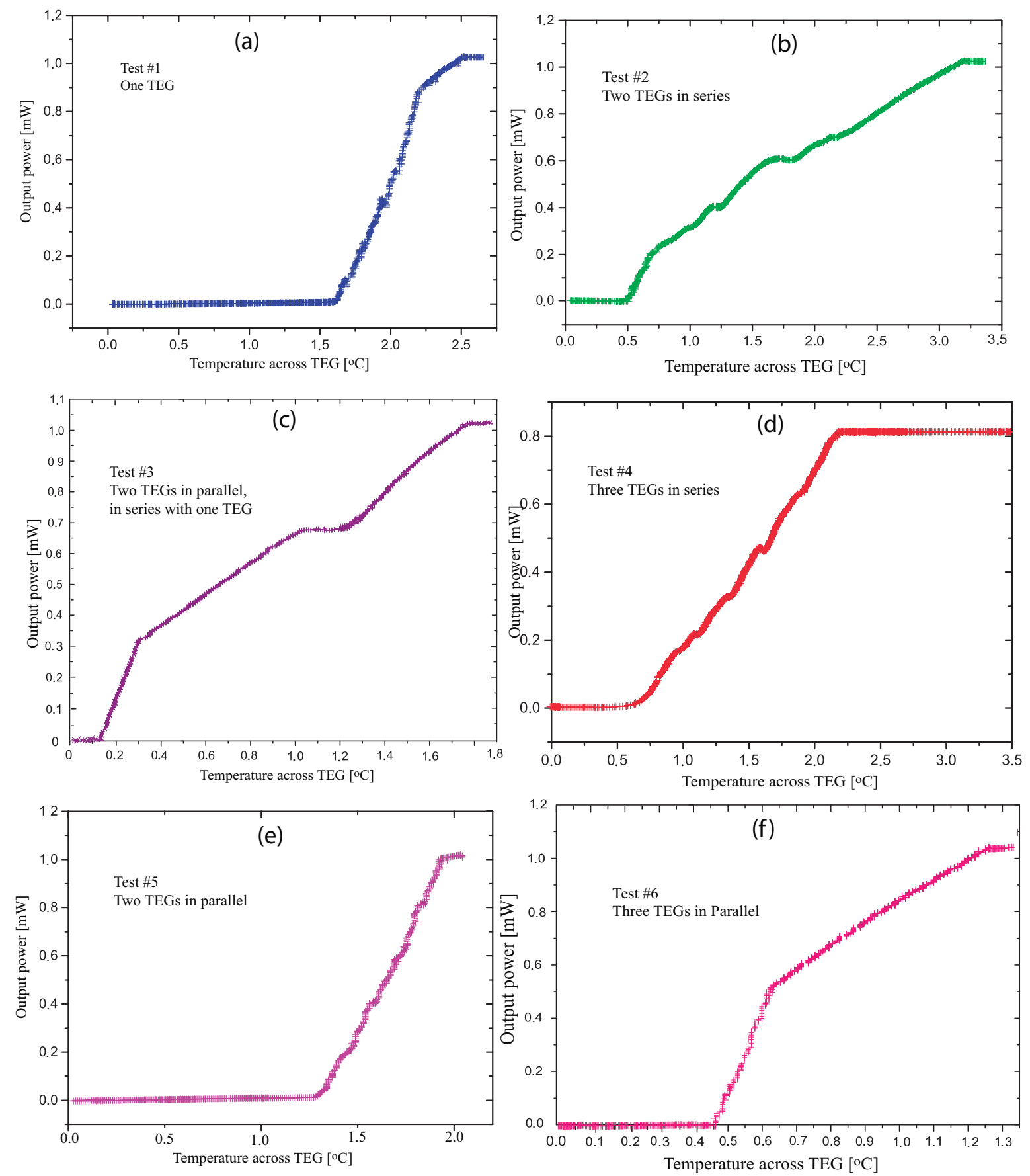

Figure 9. Calculated output power as a function of the temperature gradient across the TEG, from the measured values of $V_{2}$ and $V_{1}\left(V_{1}\right.$ verified to be always at $4.2 \mathrm{~V}$ when $V_{2} \neq 0$ ), for all tests: (a) one single TEG; (b) two TEGs in series; (c) two TEGs in parallel in series with 1 TEG; (d) three TEGs in series; (e) two TEGs in parallel; (f) three TEGs in paralell.

It is interesting to compare the results from test \#5, two TEGs in parallel, (Figure 9e) with test \#2, two TEGs in series (Figure 9b), since both tests use the same number of TEGs. The use of parallel TEGs shifts the onset of the EM8900 (from $\Delta T \approx 0.5{ }^{\circ} \mathrm{C}$ to $\Delta T \approx 1.3{ }^{\circ} \mathrm{C}$ ) but reduces significantly 
the necessary temperature gradient to achieve the maximum furnished power, from $\Delta T \approx 3.25^{\circ} \mathrm{C}$ to $\Delta T \approx 1.8^{\circ} \mathrm{C}$.

Finally, we tested a configuration with three TEGs in parallel (test \#6). The results, shown in Figure $9 \mathrm{f}$, indicates that this configuration has the same low temperature gradient onset for the energy harvesting as in tests \#2, \#3 and \#4), which can only be explained due to the much lower output impedance of test \#6 configuration. The necessary temperature gradient to achieve the maximum furnished power is the smallest found in all tests, only $\Delta T \approx 1.25^{\circ} \mathrm{C}$.

Table 2 shows the results from all six tests.

Table 2. Compilation of test results.

\begin{tabular}{lccc}
\hline Test \# & $\begin{array}{c}\text { Onset of Energy } \\
\text { Harvesting }\left[{ }^{\circ} \mathbf{C}\right]\end{array}$ & $\begin{array}{c}\text { Maximum Power } \\
\text { Achieved at }\left[{ }^{\circ} \mathbf{C}\right]\end{array}$ & $\begin{array}{c}\text { Number of } \\
\text { TEGs Used }\end{array}$ \\
\hline 1 (one TEG) & 1.7 & 2.5 & 1 \\
2 (two TEGs in series) & 0.5 & 3.25 & 2 \\
3 (two TEGs in parallel in series with one TEG) & 0.18 & 1.8 & 3 \\
4 (three TEGs in series) & 0.5 & 2.25 & 3 \\
5 (two TEGs in parallel) & 1.3 & 1.8 & 2 \\
6 (three TEGs in paralel) & 0.45 & 1.25 & 3 \\
\hline
\end{tabular}

\section{Discussion}

The presented study shows that the findings presented in the literature concerning the maximum power furnished by series and parallel connection of TEGs at high temperature differences across their hot and cold sides do not apply when we are using low temperatures and an ultra-low voltage DC-DC converter.

When TEGs are used to power a well-known load, there are software tools, like the Thermal Wizard from Laird Thermal Systems (Morrisville, NC, USA) [20], that can predict and calculate the expected power output based on a given set of thermal and electrical operating points. However, systems composed of TEGs with output voltages in the order of $5 \mathrm{mV}$ to $200 \mathrm{mV}$ cannot drive directly a load, and need to be connected to ultra-low voltage DC-DC converters, which present performance that is extremely dependent on the output impedance of the TEGs.

The optimal configuration of such a system is hard to predict theoretically because of the nonlinear behavior of the DC-DC converter both as a function of the voltage and the TEGs' output impedance.

For such systems, after the thermal operation conditions are determined, it is necessary to perform an experimental study, as we present in this work, to determine which are the optimal working conditions, in order to maximize the output power in the DC-DC converter. Performing the experimental study reduces the time-to-market and optimizes the cost/benefit of the project since it is possible to choose the optimal number of TEGs to achieve the desired DC-DC output power.

The values presented in Table 2 show that, depending on the temperature gradients available for the harvesting system, the designer has several options to choose. We observed variations of: (a) $240 \%$ in the temperature gradients required for the the onset of energy harvesting; and (b) $160 \%$ in the temperature gradients required for obtaining maximum power in the harvesting system. It is worth noticing that, due to the different output impedance of each TEG ensemble, the configuration with three TEGs in parallel (lower input open voltage) performs much better than the configuration with three TEGs in series, although this result is not intuitive.

\section{Conclusions}

We have developed a circuit that behaves as a controlled electronic load, to be used in tests of DC-DC converters operating with ultra-low input voltages. The circuit controls a current source that keeps the output voltage of the DC-DC converter at its maximum nominal value. The current drained from the DC-DC converter output is measured using a shunt resistor and an instrumentation 
amplifier. Using the measured values of the DC-DC converter output voltage and current, the power furnished by the energy harvesting system is calculated. Tests performed with several configurations of TEGs showed that the use of such a measuring circuit is mandatory to find the TEG configuration that optimizes the performance of the thermoelectric energy harvesting systems for a given range of temperature gradients.

Author Contributions: Conceptualization, J.S.D. and P.C.-D.; validation, L.D., A.S. and F.M.; test rig construction, A.S., K.d.P. and T.M.; laboratory measurements, J.S.D., F.M., A.S. and T.M.; formal analysis, J.S.D. and A.C.; writing —original draft preparation, J.S.D. and P.C.-D.; writing—review, L.D. and A.C. All authors have read and agreed to the published version of the manuscript.

Funding: This research was funded by Coordenação de Aperfeiçoamento de Pessoal de Nivel Superior, CAPES-Brazil (funding code:001) and by Graduate Program in Electrical Engineering, Federal University of Santa Catarina.

Acknowledgments: The authors thank EM Microelectronic, Switzerland for furnishing the samples of the EM8900.

Conflicts of Interest: The authors declare no conflict of interest.

\section{References}

1. Gould, C. Thermoelectric Energy Harvesting. IntechOpen 2019. [CrossRef]

2. Enescu, D. Thermoelectric Energy Harvesting: Basic Principles and Applications. IntechOpen 2019. [CrossRef]

3. Massaguerb, A.; Pujol, T.; Comamala, M.; Massaguera, E. Feasibility study on a vehicular thermoelectric generator coupled to an exhaust gas heater to improve aftertreatment's efficiency in cold-starts. Appl. Therm. Eng. 2020, 167, 114702. [CrossRef]

4. Comamala, M.; Cózar, I.R.; Massaguer, A.; Massaguer, E.; Pujol, T. Effects of Design Parameters on Fuel Economy and Output Power in an Automotive Thermoelectric Generator. Energies 2018, 11, 3274. [CrossRef]

5. Im, J.-P.; Kim, J.H.; Lee, J.W.; Woo, J.Y.; Im, S.Y.; Kim, Y.; Eom, Y.-S.; Choi, W.C.; Kim, J.S.; Moon, S.E. Self-Powered Autonomous Wireless Sensor Node by Using Silicon-Based 3D Thermoelectric Energy Generator for Environmental Monitoring Application. Energies 2020, 13, 674. [CrossRef]

6. Dias, P.C.; Cadavid, D.; Ortega, S.; Ruiz, A.; França, M.; Morais, F.; Ferreira, E.; Cabot, A. Autonomous soil moisture sensor based on nanostructured thermosensitive resistors powered by an integrated thermoelectric generator. Sens. Actuator A Phys. 2016, 239, 1-7. [CrossRef]

7. Wang, Y.; Yang, L.; Shi, X.; Chen, L.; Dargusch, M.S.; Zou, J.; Chen, Z. Flexible Thermoelectric Materials and Generators: Challenges and Innovations. Adv. Mater. 2019, 31, 1807916. [CrossRef]

8. Carvalhaes Dias, P.; Morais, F.; França, M.; Ferreira, E.; Cabot, A.; Siqueira Dias, J. Autonomous Multisensor System Powered by a Solar Thermoelectric Energy Harvester with Ultralow-Power Management Circuit. IEEE Trans. Instrum. Meas. 2015, 64, 2918-2925. [CrossRef]

9. Carvalhaes Dias, P.; Morais, F.; França, M.; Ferreira, E.; Cabot, A.; Siqueira Dias, J. Evaluation of the Thermoelectric Energy Harvesting Potential at Different Latitudes Using Solar Flat Panels Systems with Buried Heat Sink. Appl. Sci. 2018, 8, 2641. [CrossRef]

10. Ultra-Low Voltage dcdc Boost Converter for Thermal Electrical Generators-EM8900 Data Sheet, EM Microelectronic-Marin. Available online: https://www.emmicroelectronic.com/sites/default/files/ products/datasheets/8900-ds.pdf (accessed on 30 April 2020).

11. Ultralow Voltage Step-Up Converter and Power Manager-LTC3108 Data Sheet, Analog Devices. Available online: https:/ / www.analog.com/media/en/technical-documentation/data-sheets/LTC3108.pdf (accessed on 30 April 2020).

12. Montecucco, A.; Siviter, J.; Knox, A. The effect of temperature mismatch on thermoelectric generators electrically connected in series and parallel. Appl. Energy 2014, 123, 47-54. [CrossRef]

13. Coupled Inductors LPR6235 Data-sheet, Document 752R-1. Coilcraft. Available online: https://www. coilcraft.com/lpr6235.cfm (accessed on 30 April 2020).

14. Attivissimo, F.; Guarnieri Calò Carducci, C.; Lanzolla, A.M.L.; Spadavecchia, M. An Extensive Unified Thermo-Electric Module Characterization Method. Sensors 2016, 16, 2114. [CrossRef] 
15. de Cerqueira Véras, J.C.; Vieira, D.A.; Melo, E.C.; de Souza, C.P. An automatic thermal cycling based test platform for thermoelectric generator testing. In Proceedings of the 2015 IEEE International Instrumentation and Measurement Technology Conference (I2MTC), Pisa, Italy, 11-14 May 2015; pp. 1949-1953.

16. Attivissimo, F.; Nisio, A.D.; Guarnieri Calò Carducci, C.; Spadavecchia, M.F. Thermal Characterization of Thermoelectric Modules Using Infrared Camera. IEEE Trans. Instrum. Meas. 2017, 6, 305-314. [CrossRef]

17. Ajiwiguna, T.A.; Ismardi, A.; Kim, S.Y. Measurement System for Thermoelectric Module. In Proceedings of the 2015 IEEE International Instrumentation and Measurement Technology Conference (I2MTC), Pisa, Italy, 11-14 May 2014; pp. 1889-1893.

18. D'Aucelli, G.M.; Giaquinto, N.; Guarnieri Calò Carducci, C.; Spadavecchia, M.; Trotta, A. Uncertainty evaluation of the Unified Method for thermo-electric module characterization. Measurement 2019, 131, 751-763. [CrossRef]

19. Di Nisio, A.; Di Noia, T.; Guarnieri Calò Carducci, C.; Spadavecchia, M. High Dynamic Range Power Consumption Measurement in Microcontroller-Based Applications. IEEE Trans. Instrum. Meas. 2016, 65, 1968-1976. [CrossRef]

20. Laird Thermal Systems, Thermal Wizard 1 Peltier Product Specification Tool. Available online: www. lairdthermal.com/thermal-wizard-\{peltier-home\} (accessed on 30 April 2020).

(C) 2020 by the authors. Licensee MDPI, Basel, Switzerland. This article is an open access article distributed under the terms and conditions of the Creative Commons Attribution (CC BY) license (http:/ / creativecommons.org/licenses/by/4.0/). 